\title{
New pre-treatment eosinophil-related ratios as prognostic biomarkers for survival outcomes in endometrial cancer
}

\author{
Katarzyna Holub* (10) and Albert Biete
}

\begin{abstract}
Background: Systemic inflammation has long been related with adverse survival outcomes in cancer patients, and its biomarkers, such as the Neutrophil-to-Lymphocyte Ratio (NLR), are recognized as poor prognostic indicators. However, the role of eosinophils in this field has been largely overlooked. Here, we describe two new pre-treatment biomarkers, expressed as Eosinophil-to-Lymphocytes Ratio (ELR) and Eosinophil*Neutrophil-to-Lymphocytes ratio (ENLR), and we analyse their impact on prognosis of endometrial cancer (EC) patients.

Methods: A total of 163 consecutive patients diagnosed with EC and treated with postoperative radiotherapy $+/-$ chemotherapy in our institution from January 2011 to December 2015 were evaluated. The cohort was divided in two groups applying the cut-off value of 0.1 and 0.5 according to ROC curve for pre-treatment ELR and ENLR, respectively. After patients' stratification according to the ESMO-ESGO-ESTRO modified risk assessment, subgroup analyses were conducted.
\end{abstract}

Results: Higher values of ELR and ENLR were associated with worse OS ( $p=0.004$ and $p=0.010$, respectively). On univariate analysis, the factors associated with shorter OS were ELR $\geq 0.1$ ( $H R=2.9, p=0.017)$, ENLR $\geq 0.5$ (HR=3.0, $p=0.015)$, advanced FIGO stage ( $H R=3.4, p=0.007)$, endometrioid histology ( $H R=0.26, p=0.003)$ and ESMO-ESGO-ESTRO high-risk $(H R=10.2, p=0.023)$. On multivariate Cox regression, higher ELR and ENLR were independently associated with a worse outcome adjusted for the standardly applied prognostic factors.

Conclusions: Increased values of ELR and ENLR portend worse OS in EC, especially in patients classified by the ESMO-ESGO-ESTRO guidelines as a high-risk group. To our best knowledge, this is the first report describing eosinophils-related ratios as prognostic biomarkers in malignant tumours.

Keywords: Endometrial cancer, Systemic inflammation, Circulating eosinophils, Neutrophil-to-lymphocyte ratio (NLR), Eosinophil-to-lymphocytes ratio (ELR), Eosinophil*neutrophil-to-lymphocytes ratio (ENLR), ESMO-ESGO-ESTRO risk assessment, Overall survival

\section{Background}

Endometrial cancer (EC) is the 5th most common form of female cancer in the USA, with 61,380 new cases diagnosed in 2017, and responsible for 10,920 deaths over the same year [1]. According to the FIGO 2009 classification, 80\% of $\mathrm{EC}$ are diagnosed in stages I-II, with 5-year survival rates of $89.6 \%$ in stage I, decreasing to $78.3 \%$ in stage II, $61.9 \%$ in stage III, and $21.1 \%$ in stage IV [2]. Although EC diagnosed in early stages is potentially curative with surgery followed

\footnotetext{
* Correspondence: holub@clinic.ub.es

Radiation Oncology Department, Hospital Clinic de Barcelona, University of Barcelona, CNillarroel 170, 08036 Barcelona, Spain
}

by adjuvant radiotherapy $+/$ - chemotherapy, about $15 \%$ of these patients present an increased risk of cancer progression [3]. This risk is assessed by the ESMO-ESGO-ESTRO risk stratification, based on tumour characteristics $[4,5]$.

However, the impact of other factors, such as systemic inflammation, is gaining importance as an indicator of poor prognostic in cancer patients $[6,7]$. The interest of this host-dependent response, expressed through prognostic ratios composed of circulating white blood cells, lies mainly on circulating neutrophils, which have been studied as neutrophil-to-lymphocytes ratio (NLR) $[8,9]$. Nonetheless, the role of other subpopulations of leukocytes,

(c) The Author(s). 2018 Open Access This article is distributed under the terms of the Creative Commons Attribution 4.0 International License (http://creativecommons.org/licenses/by/4.0/), which permits unrestricted use, distribution, and reproduction in any medium, provided you give appropriate credit to the original author(s) and the source, provide a link to the Creative Commons license, and indicate if changes were made. The Creative Commons Public Domain Dedication waiver (http://creativecommons.org/publicdomain/zero/1.0/) applies to the data made available in this article, unless otherwise stated. 
such as eosinophils, has been largely overlooked in tumour progression [10]. Although some reports dating from the 1950s already suggested the role of circulating eosinophils as a biomarker of tumour persistence or recurrence after radiotherapy, recent studies confirm that eosinophils act as an important modulator and effector of both innate and adaptive immune response [11-15]. Eosinophils link two different mechanisms of host defence: against allergens and against malignancies, as they secret cytokines, which guide CD8 (+) T cells and enhance their infiltration into the tumour, and induce the barrier permeability [16-19]. Recently, a high level of blood eosinophils was associated with better survival in metastatic melanoma [20].

Nonetheless, their role in cancer progression remains controversial as they may be considered as tumour-associated tissue eosinophilia (TATE) or as tumour-associated blood eosinophilia (TABE) $[16,21,22]$. Classically, TATE is more often reported in the literature and generally considered as a favourable prognosticator, while TABE is usually described as a consequence of tumour necrosis in advanced disease, hence related to poorer outcomes [23, 24]. Some authors suggest that the release of damage-associated molecular patterns (DAMPs) during tumour necrosis causes immunosuppression in tumour microenvironment and recruits diverse inflammatory cells, including circulating eosinophils, which limit the biologic activity of DAMPs $[25,26]$. This mechanism may clarify why TATE has been long associated with an improved prognosis and may be the reason for the inverse association between atopic disease and the risk of cancer [27, 28].

The aim of the present study was to explore the impact of the level of pre-treatment circulating eosinophils and lymphocytes, expressed as ratios, on survival outcomes in EC patients.

\section{Methods}

After the Institutional Review Board approval, a review of our department's database of patients with EC treated at our institution with external beam radiotherapy (EBRT) and/or High Dose Rate Brachytherapy (HDR-BT) in a period of five years was conducted. All patients included signed the informed consent for treatment and data processing.

\section{Patients' characteristics}

The data of 163 patients diagnosed with histologically confirmed EC and treated with postoperative radiotherapy at our centre from January 2011 to December 2015 were retrospectively reviewed. All patients underwent hysterectomy as a first treatment, with laparoscopic pelvic paraaortic lymphadenectomy in 107 cases (81.7\%), and had pre-treatment blood test results done within 3 months before surgery. Patients diagnosed with acute or chronic infections, including human immunodeficiency virus (HIV), any type of immunodeficiency, other active malignancies, haematological disorders, steroid or anti-inflammatory treatment for any reason, were excluded. The median age at diagnosis was 65 years (y), mean 64.79, range 41-90. The most frequent histology was endometrioid carcinoma (73.3\%). The disease stage was classified as non-advanced (stage I-II) in 98 patients (74.8\%).

The combination of EBRT and HDR-BT was administered to 88 patients (65.2\%), with a mean dose of 53.4 Gray (Gy) (range $21-75)$. Only 43 patients $(32.8 \%)$ were treated exclusively with HDR-BT (mean dose 10.0 Gy, range 7-20). All patients were stratified into six risk groups according to ESMO-ESGO-ESTRO anatomopathological features [4]. Patients' characteristics are detailed in Table 1.

\section{Follow-up results}

The follow up (FU) was performed, as suggested by ESMO guidelines, every 3-4 months for the first 2 years, and then every 6 months for the next 3 years.

\section{Systemic inflammation biomarkers}

The level of eosinophils in pre-treatment blood tests was analysed. We created two groups using a 0.1 cut-off according to the best receiver operating characteristics (ROC) curve value: patients with absolute eosinophil count $(\mathrm{AEC}) \geq 0.1 \quad(n=112)$ vs. $\mathrm{AEC}<0.1 \quad(n=19)$, and we evaluated the influence of high AEC on patients' survival outcomes.

Afterwards, we described two new systemic inflammatory biomarkers, expressed as follows: Eosinophilto-Lymphocytes Ratio (ELR) and Eosinophil*Neutrophil-to-Lymphocytes Ratio (ELR multiplied by the absolute neutrophil count, ENLR), and we analysed their impact on overall survival (OS) and progression free survival (PFS). Additionally, we evaluated the same ratios based on posttreatment blood tests.

\section{Statistical analysis}

All statistical tests were two-sided and statistical significance was defined as $p<0.05$. Summarized data are presented as numbers and percentages unless otherwise stated.

The primary endpoint was OS and the secondary endpoint was PFS. Predefined subgroup analysis was conducted based on the ESMO-ESGO-ESTRO risk stratification, which subsequently was converted into a binary variable by creating a low (groups 1-3) and a high-risk cohort (groups 4-5).

Afterwards, the study population was subdivided into two groups, based on the cut-offs for ELR and ENLR, separately. Both ELR and ENLR were defined as binary variables by finding the cut-off value from a ROC curve. The binary variables' balance across prognostic characteristics was assessed using Chi-square test (X2 test). Frequencies were compared using Fisher's exact test for categorical variables. Kaplan Meier's curves were displayed 
Table 1 Characteristics of all patients included in the study $(n=163$ ), comparison of these characteristics according to ELR (cut-off $\geq 0.1$ ) and ENLR (cut-off $\geq 0.5$ )

\begin{tabular}{|c|c|c|c|c|c|c|c|}
\hline Patients' characteristics & $\begin{array}{l}\text { All patients included } \\
(n=163, \% \text { of total) }\end{array}$ & $\begin{array}{l}\text { ELR }<0.1 \\
n=117(\%)\end{array}$ & $\begin{array}{l}\text { ELR } \geq 0.1 \\
n=46(\%)\end{array}$ & $p$-value ${ }^{*}$ & $\begin{array}{l}\text { ENLR }<0.5 \\
n=118(\%)\end{array}$ & $\begin{array}{l}\text { ENLR } \geq 0.5 \\
n=45(\%)\end{array}$ & $p$-value* \\
\hline \multicolumn{8}{|l|}{ Age at diagnosis (years): } \\
\hline$<65$ years: & $74(45.4 \%)$ & $4(73.0 \%)$ & $20(27.0)$ & \multirow[t]{2}{*}{.757} & $53(71.6 \%)$ & $21(28.4 \%)$ & \multirow[t]{2}{*}{.410} \\
\hline$\geq 65$ years: & $89(54.6 \%)$ & $63(70.8 \%)$ & $26(29.2)$ & & $65(73.0 \%)$ & $24(27.0 \%)$ & \\
\hline \multicolumn{8}{|l|}{ FIGO 2009 stage at diagnosis: } \\
\hline$\cdot \mid A$ & $4(26.0 \%)$ & $34(7.1 \%)$ & $9(0.9 \%)$ & \multirow[t]{9}{*}{.070} & $33(76.7 \%)$ & $10(23.3 \%)$ & \multirow[t]{9}{*}{.136} \\
\hline$\cdot \mid \mathrm{B}$ & $54(33.2 \%)$ & $33(61.1 \%)$ & $21(38.9 \%)$ & & 35 64.8\%) & $19(35.2 \%)$ & \\
\hline$\cdot \|$ & $24(14.0 \%)$ & 19 (79.2\%) & $5(20.8 \%)$ & & $18(75.0 \%)$ & $6(25.0 \%)$ & \\
\hline$\cdot \| A$ & $9(5.5 \%)$ & $4(44.4 \%)$ & $5(55.6 \%)$ & & $5(55.6 \%)$ & $4(44.4 \%)$ & \\
\hline$\cdot \| \mathrm{B}$ & 0 & 0 & 0 & & 0 & 0 & \\
\hline$\cdot \| \mathrm{IIC} 1$ & $15(9.2 \%)$ & $13(86.7 \%)$ & $2(13.3 \%)$ & & $14(93.3 \%)$ & $1(6.7 \%)$ & \\
\hline$\cdot \| I \mid C 2$ & $7(4.3 \%)$ & $7(100 \%)$ & 0 & & $7(100 \%)$ & 0 & \\
\hline • IVA & $9(5.5 \%)$ & $6(66.7 \%)$ & $3(33.3 \%)$ & & $5(55.6 \%)$ & $4(44.4 \%)$ & \\
\hline$\cdot$ IVB & $2(1.2 \%)$ & $1(50 \%)$ & $1(50 \%)$ & & $1(50.0 \%)$ & $1(50.0 \%)$ & \\
\hline \multicolumn{8}{|c|}{ Patients in advanced stage (FIGO I-II vs. FIGO III-IV) (n,\%): } \\
\hline No (FIGO I-II) & $121(74.2 \%)$ & $85(70.2 \%)$ & $36(29.8 \%)$ & \multirow[t]{2}{*}{.461} & $85(70.2 \%)$ & $36(29.8 \%)$ & \multirow[t]{2}{*}{.299} \\
\hline Yes (FIGO III-IV) & $42(25.8 \%)$ & $32(76.2 \%)$ & $10(23.8 \%)$ & & $33(78.6 \%)$ & $9(21.4 \%)$ & \\
\hline \multicolumn{8}{|l|}{ Tumour grade $(n, \%)$ : } \\
\hline 1 & $36(22.1 \%)$ & $24(66.7 \%)$ & 12(33.3\%) & \multirow[t]{3}{*}{.736} & $26(72.2 \%)$ & $10(27.8 \%)$ & \multirow[t]{3}{*}{.772} \\
\hline 2 & $61(37.4 \%)$ & $45(73.8 \%)$ & $16(26.2 \%)$ & & $46(75.4 \%)$ & $15(24.6 \%)$ & \\
\hline 3 & $66(40.5 \%)$ & $48(72.7 \%)$ & 18(27.3\%) & & $46(69.7 \%)$ & $20(30.3 \%)$ & \\
\hline \multicolumn{8}{|c|}{ Patients with tumour grade 3 vs. tumour grade $1-2(n, \%)$ : } \\
\hline Grade 1-2 & $97(59.5 \%)$ & $66(68.0 \%)$ & $31(32.0 \%)$ & \multirow[t]{2}{*}{.865} & $72(74.2 \%)$ & $25(25.8 \%)$ & \multirow[t]{2}{*}{.593} \\
\hline Grade 3 & $66(40.5 \%)$ & $46(69.7 \%)$ & $20(30.3 \%)$ & & $46(69.7 \%)$ & $20(30.3 \%)$ & \\
\hline \multicolumn{8}{|l|}{ Tumour histology $(n, \%)$ : } \\
\hline Endometrioid & $119(73 \%)$ & $85(71.4 \%)$ & $34(28.6 \%)$ & \multirow[t]{8}{*}{.305} & $87(73.1 \%)$ & $32(26.9 \%)$ & \multirow[t]{8}{*}{.424} \\
\hline Serous-papillary & $14(8.6 \%)$ & $12(85.7 \%)$ & $2(14.3 \%)$ & & $10(71.4 \%)$ & $4(28.6 \%)$ & \\
\hline Clear cell & $5(3.1 \%)$ & $5(100 \%)$ & 0 & & $5(100 \%)$ & 0 & \\
\hline Squamous & $6(3.7 \%)$ & $3(50.0 \%)$ & $3(50.0 \%)$ & & $3(50.0 \%)$ & $3(50.0 \%)$ & \\
\hline Villoglandular & $2(1.2 \%)$ & $1(50.0 \%)$ & $1(50.0 \%)$ & & $1(50.0 \%)$ & $1(50.0 \%)$ & \\
\hline Sarcoma (not LMS or carcinosarcoma) & $2(1.2 \%)$ & $2(100 \%)$ & 0 & & $2(100 \%)$ & 0 & \\
\hline Leiomyosarcoma & $3(1.8 \%)$ & $1(33.3 \%)$ & $2(66.7 \%)$ & & $1(33.3 \%)$ & $2(66.7 \%)$ & \\
\hline Carcinosarcoma & $12(7.4 \%)$ & $8(66.7 \%)$ & $4(33.3 \%)$ & & $9(75.0 \%)$ & $3(25.0 \%)$ & \\
\hline \multicolumn{8}{|l|}{ Lymphadenectomy (n,\%): } \\
\hline No & $29(17.8 \%)$ & 19 (65.6\%) & $10(34.5 \%)$ & \multirow[t]{2}{*}{.409} & 19 (65.5\%) & $10(34.5 \%)$ & \multirow[t]{2}{*}{.361} \\
\hline Yes & $134(82.2 \%)$ & $98(73.1 \%)$ & $36(26.9 \%)$ & & 99 (73.9\%) & $35(26.1 \%)$ & \\
\hline \multicolumn{8}{|c|}{ ESMO-ESGO-ESTRO (ESMO 2015) risk groups ( $n, \%)$ : } \\
\hline 1 - Low & $28(17.2 \%)$ & $21(75.0 \%)$ & $7(25.0 \%)$ & \multirow[t]{6}{*}{.775} & $21(75.0 \%)$ & $7(25.0 \%)$ & \multirow[t]{6}{*}{.440} \\
\hline 2 - Intermediate & $31(19.0 \%)$ & $20(64.5 \%)$ & $11(35.5 \%)$ & & 21 (67.7\%) & $10(32.3 \%)$ & \\
\hline 3- High-Intermediate & $13(8.0 \%)$ & $9(69.2 \%)$ & $4(30.8 \%)$ & & $8(61.5 \%)$ & $5(38.5 \%)$ & \\
\hline 4 - High & 75 (46.0\%) & $57(76.0 \%)$ & $18(24.0 \%)$ & & 59 (78.7\%) & $16(21.3 \%)$ & \\
\hline 5 - Advanced & $14(8.6 \%)$ & $9(64.3 \%)$ & $5(35.7 \%)$ & & $8(57.1 \%)$ & $6(42.9 \%)$ & \\
\hline 6 - Metastatic & $2(1.2 \%)$ & $1(50.0 \%)$ & $1(50.0 \%)$ & & $1(50.0 \%)$ & $1(50.0 \%)$ & \\
\hline
\end{tabular}

Patients in high-risk groups according to ESMO-ESGO-ESTRO risk classification $(n, \%)$ : 
Table 1 Characteristics of all patients included in the study $(n=163$ ), comparison of these characteristics according to ELR (cut-off $\geq 0.1$ ) and ENLR (cut-off $\geq 0.5$ ) (Continued)

\begin{tabular}{|c|c|c|c|c|c|c|c|}
\hline Patients' characteristics & $\begin{array}{l}\text { All patients included } \\
(n=163, \% \text { of total) }\end{array}$ & $\begin{array}{l}\text { ELR }<0.1 \\
n=117(\%)\end{array}$ & $\begin{array}{l}E L R \geq 0.1 \\
n=46(\%)\end{array}$ & $p$-value* & $\begin{array}{l}\text { ENLR }<0.5 \\
n=118(\%)\end{array}$ & $\begin{array}{l}\text { ENLR } \geq 0.5 \\
n=45(\%)\end{array}$ & $p$-value \\
\hline Low (risk group 1-3) & $72(44.2 \%)$ & $47(65.3 \%)$ & $25(34.7 \%)$ & .496 & $50(69.4 \%)$ & $22(30.6 \%)$ & .484 \\
\hline High (risk group 4-6) & $91(55.8 \%)$ & $65(71.4 \%)$ & $26(28.6 \%)$ & & $68(74.7 \%)$ & $23(25.3 \%)$ & \\
\hline \multicolumn{8}{|c|}{ Brachytherapy exclusive $(n, \%)$ : } \\
\hline No & $110(67.5 \%)$ & 75 (68.2\%) & $35(31.8 \%)$ & .142 & $77(70.0 \%)$ & $33(30.0 \%)$ & .325 \\
\hline Yes & $53(32.5 \%)$ & $42(79.2 \%)$ & $11(20.8 \%)$ & & $41(77.4 \%)$ & $12(22.6 \%)$ & \\
\hline \multicolumn{8}{|l|}{ Chemotherapy (n,\%): } \\
\hline No & $104(63.8 \%)$ & $72(69.2 \%)$ & $32(30.8 \%)$ & .337 & 71 (68.3\%) & $33(31.7 \%)$ & .118 \\
\hline Yes & $59(36.2 \%)$ & $45(76.3 \%)$ & $14(23.7 \%)$ & & 47 (79.7\%) & $12(20.3 \%)$ & \\
\hline
\end{tabular}

* X2 test or T-student test

to evaluate the prognostic value of ELR and ENLR for OS and PFS. Survival outcomes were calculated from the date of surgery to the event occurrence, which is progression or cancer-related death in the case of PFS, or any death in the case of OS. If no event occurred, patients were censored at the time they were last known to be event free. All survival outcomes were analysed using Log rank test (LR), Breslow test (BR) was additionally applied.

The univariate and multivariate Cox regression models were used to assess the prognostic effect of inflammatory biomarkers and included binary variables: ELR ( $\geq 0.1$ vs. $<0.1)$, ENLR ( $\geq 0.5$ vs. $<0.5)$, age $(\geq 65 y$ vs. $<65 y)$, ESMO-ESGO-ESTRO high-risk (groups 4-6) vs. low-risk (groups 1-3), high grade (grade 3 vs. grade 1-2), advanced FIGO 2009 stage (stage III-IV vs. stage I-II), endometrioid histology (vs. other tumour histology). All statistical analyses were performed using SPSS v. 23.

\section{Results}

\section{Survival outcomes of the entire cohort}

All survival outcomes were expressed in months. After a median follow-up of 54.8 (range 24.6-58.4), progression was observed in 36 patients (22.1\%). There was no exclusive local recurrence and only one patient developed exclusive regional recurrence (progression in pelvic node). Both local and regional recurrence, were observed in $10.7 \%$ of patients $(n=14)$, while $17.6 \%(n=23)$ presented distant metastasis. Median PFS for the entire cohort was of 23.1 (range 0.2-62.2). At the moment of data collection, 21 deaths were reported (12.33\%), 20 of them were related to cancer (12.27\%). All details concerning the survival outcomes according to the ESMO-ESGO-ESTRO risk groups are included in Table 2.

\section{ELR}

The mean value of ELR was 0.08 (SD 0.065, range 0.0-0.31, median 0.063). Using the cut-off of 0.1 according to the ROC with the Area Under Curve (AUC) of 0.61, we divided the entire cohort into two groups: $\operatorname{ELR} \geq 0.1(n=46)$ and ELR $<0.1 \quad(n=117)$. Patients' characteristics of the two comparative groups are included in Table 1.

OS in the group with ELR $\geq 0.1$ was 50.7 months (IC 95\% $43.8-57.6$ ) vs. 62.3 months (IC 95\% 59.0-65.5) in the group with ELR $<0.1$ (LR $p=0.004, \mathrm{X} 2=6.3$; BR $p=0.026$, $\mathrm{X} 2=4.9$ ), HR 2.9, $p=0.017$ (Fig. 1).

Eleven events were reported in the high ELR group (23.9\% of patients) vs. 10 events $(8.6 \%)$ in the low ELR group (LR: $\mathrm{p}=0.01, \mathrm{X} 2=6.5 ; \mathrm{BR}: \mathrm{p}=0.026, \mathrm{X} 2=4.9$ ).

Regarding the data of the entire cohort, PFS of patients according to ELR level was not significantly different ( $\mathrm{LR} p=0.095$, BR $p=0.08$ ). However, the number of events was higher in patients with $E L R \geq 0.1$ (14 events vs. 22 events, which meant $30.4 \%$ vs. $18.8 \%$ patients with progression, respectively).

ELR was not correlated with patient's age $(p=0.90)$, FIGO stage at diagnosis $(p=0.77)$, tumour histology $(p=0.94)$ or tumour grade $(p=0.86)$.

\section{ENLR}

The mean value of ENLR was 0.448 (SD 0.59, range 0-5.54, median 0.31). Using the cut-off of 0.5 (ROC curve AUC $=0.621$ ), we divided the entire cohort into two groups: ENLR $\geq 0.5(n=45)$ and ENLR $<0.5(n=118)$. Patients' characteristics of the two comparative groups are included in Table 1.

Median OS in the group with ENLR $\geq 0.5$ was 49.8 months (IC 95\% 43.8-55.8) vs. 61.9 months (IC 95\% 58.665.2) in the group with ENLR $<0.5$ (LR: $p=0.01, \mathrm{X} 2=$ 6.6; BR: $p=0.026, \mathrm{X} 2=4.9, \mathrm{HR}=3.0, p=0.015$, Fig. 2). Ten events were reported in the high ENLR group (which meant $22.2 \%$ of patients) vs. 11 events $(9.3 \%)$ in the low ENLR group.

Median PFS according to ENLR level was not significantly different (LR: $p=0.1, \mathrm{BR}: p=0.09$ ).

ENLR $<0.5$ was not correlated with patients' age $(p=0.81)$, FIGO stage at diagnosis $(p=0.22)$, tumour histology $(p=0.63)$ or tumour grade $(p=0.59)$. 
Table 2 Patients's status at the end of the study according to ESMO-ESGO-ESTRO modified risk assessment (ESMO 2015)

\begin{tabular}{|c|c|c|c|c|c|}
\hline \multirow{2}{*}{$\begin{array}{l}\text { ESMO } \\
2015 \\
\text { risk } \\
\text { group }\end{array}$} & \multicolumn{5}{|c|}{ Status of patients at the end of the study $(n=163)$} \\
\hline & Alive (no evidence of disease) & Disease progression & Cancer-related death & Non cancer related death & Total \\
\hline 1 & $27(20.8 \%)$ & $1(8.33 \%)$ & 0 & 0 & $28(17.2 \%)$ \\
\hline 2 & $30(23.1 \%)$ & 0 & 0 & $1(100 \%)$ & $31(19.0 \%)$ \\
\hline 3 & $11(8.4 \%)$ & 0 & $2(10 \%)$ & 0 & $13(8.0 \%)$ \\
\hline 4 & $57(43.8 \%)$ & $7(58.33 \%)$ & $11(55 \%)$ & 0 & $75(46.0 \%)$ \\
\hline 5 & $5(3.9 \%)$ & $4(33.33)$ & $5(25 \%)$ & 0 & $14(8.6 \%)$ \\
\hline 6 & 0 & 0 & $2(10 \%)$ & 0 & $2(1.2 \%)$ \\
\hline Total & $130(100 \%)$ & $12(100 \%)$ & $20(100 \%)$ & 1 (100\%) & 163 (100\%) \\
\hline
\end{tabular}

\section{ELR and ENLR as independent prognostic factors}

On univariate analysis, worse OS was associated with ELR $\geq$ $0.1(\mathrm{HR}=2.9, p=0.017), \mathrm{ENLR} \geq 0.5(\mathrm{HR} 3.0, p=0.015)$, ESMO-ESGO-ESTRO high-risk (HR =4.7, $p=0.014)$, tumour grade $3(\mathrm{HR}=8.1, p=0.001)$ and advanced stage $(\mathrm{HR}=3.4, p=0.007)$, while endometrioid histology was associated with better prognosis $(\mathrm{HR}=0.3, p=0.003)$. Age $\geq 65$ years did not reach significance, $p=0.055$ (Table 3 ). All variables included in univariate analysis were evaluated in all patients using X2 tests (Table 1, Additional file 1: Figure S1, Additional file 2: Figure S2, Additional file 3: Figure S3, Additional file 4: Figure S4, and Additional file 5: Figure S5).

On multivariate analysis, carried out separately for ELR and ENLR, the impact of variables used in univariate analysis on the principal endpoint (OS) was evaluated. Three variables reached statistical significance: $E L R \geq 0.1(\mathrm{HR}=4.9$, $p=0.001)$, ENLR $\geq 0.5(\mathrm{HR}=3.9, p=0.003)$, and tumour grade $3(p=0.003$ in ELR model and $p=0.007$ in ENLR model). Age $\geq 65$ was statistically significant only in ENLR model $(p=0.043)$ (Table 3$)$.

\section{Subgroups according to ESMO-ESGO-ESTRO modified risk assessment}

According to the ESMO-ESGO-ESTRO risk classification, all patients were allocated to six different risk groups (Table 1). Thus, we divided the entire cohort into two groups: low-risk (groups 1-3) and high-risk cohort (groups 4-6).

In the high-risk cohort $(n=91), 34.6 \%$ of patients with ELR $\geq 0.1$ died and OS was of 44.9 months (IC 95\% 35.9-53.9) vs. 59.6 months (54.7-64.5) in the low ELR group with $13.8 \%$ of patients dead at the end of the study (LR: $p=0.009, \mathrm{X} 2=6.8, \mathrm{BR}: p=0.015, \mathrm{X} 2=5.9$,

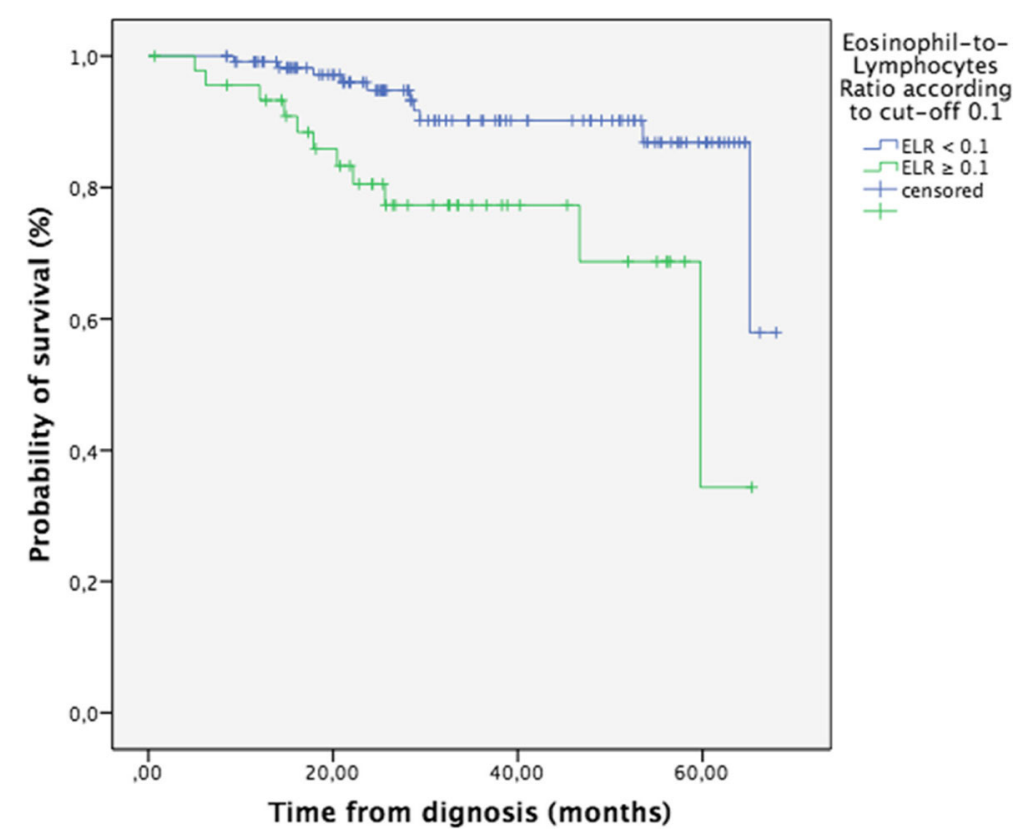

Fig. 1 Overall survival of patients with endometrial cancer $(n=163)$ according to the Eosinophil-to-Lymphocytes Ratio (ELR, cut-off $\geq 0.1)$, $p=0.004$ 


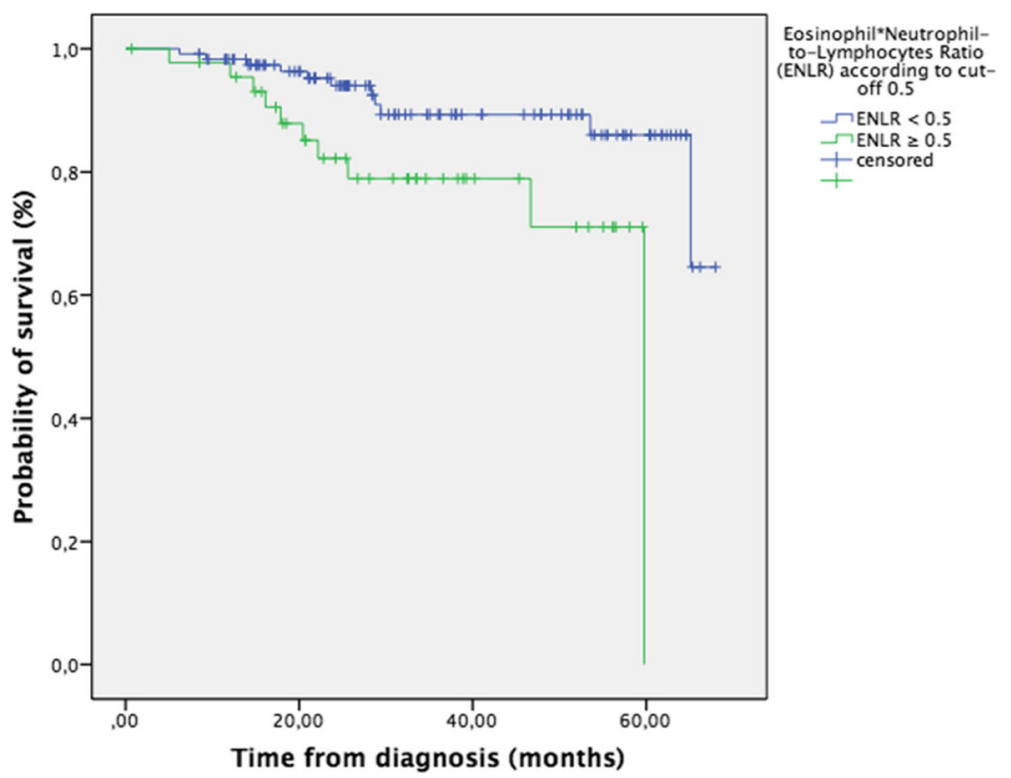

Fig. 2 Overall survival of patients with endometrial cancer $(n=163)$ according to the Eosinophi**Neutrophil-to-Lymphocytes Ratio (ENLR, cut-off $\geq 0.5), p=0.010$

Additional file 6: Figure S6). PFS was not significantly different between the two groups $(p=0.10)$.

Patients in the ENLR $\geq 0.5$ cohort showed a worse OS of 45.5 months (IC 95\%, 36.2-54.9) vs. 59.0 months in ENLR $<0.5$ (IC 95\%, 54.1-64.0, LR: $p=0.020, \mathrm{X} 2=5.4$, BR: $p=$ $0.047, \mathrm{X} 2=3.9$, Additional file 7: Figure S7). PFS was not significantly different between the two groups $(p=0.18)$.

In the low-risk cohort $(n=72)$, patients with ELR $\geq 0.1$ $(n=25)$ and patients with ENLR $\geq 0.5(n=22)$ failed to show statistically significant differences regarding OS and PFS.

\section{Absolute eosinophil count (AEC)}

Pre-treatment blood eosinophilia, defined as an absolute eosinophils count $\geq 0.65 \times 10^{9} / \mathrm{L}$, was detected in our cohort only in 6 patients (4.6\%), all of them alive and with no evidence of disease progression at the moment of data collection. The mean value of AEC was 0.1 (SD 0.13, range $0-0.8$, median 0.152 ). There were no statistical differences in OS (55.6 months vs. 61.35 months, $p=0.154, \mathrm{X} 2=$ $2.04)$ nor PFS $(p=0.772, \mathrm{X} 2=0.08)$ between the group with $\mathrm{AEC} \geq 0.1$ and the one with $\mathrm{AEC}<0.1$.

\section{Leucocytosis, neutrophilia and NLR}

Patients that presented a high level of circulating WBC (leukocytes $>11,000 \times 10^{9} / \mathrm{L}$ or neutrophils $>7000 \times 10^{9} / \mathrm{L}$ ) or NLR $\geq 2.4$ (cut-off according to ROC curve, AUC 0.516) at cancer diagnosis did not show statistical difference in OS compared to patients with lower levels $(p=0.51, p=0.23$ and $p=0.63$, respectively).

Table 3 Impact of ELR and ENLR on overall survival (OS): Kaplan Meier survival analysis, univariate and multivariate Cox regression (models for ELR and ENLR, respectively), $n=163$

\begin{tabular}{|c|c|c|c|c|c|c|c|c|}
\hline \multirow[t]{2}{*}{ Variables } & \multicolumn{2}{|c|}{$\begin{array}{l}\text { Kaplan-Meier } \\
\text { survival analysis }\end{array}$} & \multicolumn{2}{|c|}{$\begin{array}{l}\text { UNIVARIATE Cox } \\
\text { regression }\end{array}$} & \multicolumn{2}{|c|}{$\begin{array}{l}\text { MULTIVARIATE Cox } \\
\text { regression for } \\
\text { ELR } \geq 0.1 \text { model }\end{array}$} & \multicolumn{2}{|c|}{$\begin{array}{l}\text { MULTIVARIATE Cox } \\
\text { regression for } \\
\text { ENLR } \geq 0.5 \text { model }\end{array}$} \\
\hline & $x 2$ & $p$-value & HR (IC 95\%) & $p$-value & HR (IC 95\%) & $p$-value & HR (IC 95\%) & $p$-value \\
\hline Age $\geq 65$ years (vs. $<65$ years) & 3.9 & 0.047 & $2.6(0.98-6.7)$ & 0.055 & $2.8(1.0-8.2)$ & 0.059 & $2.8(1.03-7.8)$ & 0.043 \\
\hline FIGO advanced stage III (vs. stage I-II) & 8.3 & 0.004 & $3.4(1.4-8.4)$ & 0.007 & $3.1(0.9-9.8)$ & 0.060 & $2.8(0.9-8.5)$ & 0.065 \\
\hline Tumour grade 3 (vs. grade 1-2) & 15.8 & 0.000 & $8.1(2.4-27.4)$ & 0.001 & $6.8(1.9-24.7)$ & 0.003 & $5.8(1.6-21.2)$ & 0.007 \\
\hline Endometroid histology (vs. other histology) & 10.1 & 0.001 & $0.3(0.1-0.63)$ & 0.003 & $0.4(0.1-1.1)$ & 0.068 & $0.4(0.14-1.2)$ & 0.099 \\
\hline ESMO-ESTRO-ESGO High Risk groups 4-6 (vs. groups 1-3) & 7.4 & 0.007 & $4.7(1.4-15.8)$ & 0.014 & $1.2(0.2-6.5)$ & 0.856 & $1.3(0.2-6.9)$ & 0.770 \\
\hline$E L R \geq 0.1$ (vs. $<0.1)$ & 6.3 & 0.004 & $2.9(1.2-6.8)$ & 0.017 & $4.9(1.9-12.4)$ & 0.001 & - & - \\
\hline ENLR $\geq 0.5$ (vs. $<0.5)$ & 6.6 & 0.010 & $3.0(1.2-7.3)$ & 0.015 & - & - & $3.9(1.6-9.8)$ & 0.003 \\
\hline
\end{tabular}

All entries in boldface reflect $p$-values $<0.05$ 


\section{Discussion}

Systemic inflammation is a recognised feature of cancer progression, and inflammatory biomarkers are a key subject of research on anti-tumour response. However, the role of eosinophils in this field has long been ignored. Even though tumour-associated blood eosinophilia is described in a wide range of tumours $[11,12,27]$, and is easily diagnosed, this finding is not so frequent in clinical practice, and only accounts for $1-7 \%$ of all eosinophilia's diagnoses [21, 29]. In accordance with these reports, we concluded that eosinophilia at cancer diagnosis was really infrequent in our cohort and had no impact on survival outcome. We hypothesise that it is not eosinophils alone, but the ratios between circulating eosinophils and lymphocytes, that may reflect the host's immunosuppression status at cancer diagnosis, and may help to achieve a more precise risk stratification of patients diagnosed with EC.

Here, we describe new eosinophil-based prognostic ratios, expressed as a relationship between different subtypes of WBC. To our best knowledge, we are the first to propose these ratios as prognostic biomarkers in malignant tumours and to apply inflammatory biomarkers as a tool to refine the ESMO-ESGO-ESTRO risk stratification in EC.

We focused our study on EC because, in spite of its generally favourable prognosis, recent studies claim that the survival outcomes depend on factors beyond the classically established risk indicators [30]. Moreover, the scientific evidence of the inflammatory biomarkers in EC is significantly lower than in other malignancies [7-9].

Our study is based on a uniformly treated cohort that includes patients of all FIGO stages if they underwent hysterectomy as a first treatment. According to the ESMO guidelines, a complete macroscopic cytoreduction is recommended even for advanced disease, while systematic pelvic lymphadenectomy should not be performed routinely, hence lymphadenectomy was performed only in $80 \%$ of patients in our study [4]. Most patients with EC usually present a low recurrence risk, but in our study $55.8 \%$ of patients $(n=91)$ belonged to the high-risk group, which may be explained by the reference status of our institution, where patients with high-risk factors are usually addressed. Although distant relapses often account for only one-third of recurrences in the literature, they were observed in $63.9 \%$ of all relapses in our cohort $[4,30]$. As most EC relapses occur within 3 years after the primary treatment, we considered that our median FU of 55.9 months (range 52.4-59.4) was long enough [4].

Due to the correlation between ELR and ENLR, two multivariate analysis models were evaluated: one for ELR $\geq 0.1(p=0.001, \quad \mathrm{HR}=4.9$, IC 95\%, 1.9-12.4 $)$ and one for ENLR $\geq 0.5(p=0.003, \mathrm{HR}=3.9$, IC 95\%, $1.6-$ 9.8). Holding the other covariates constant, higher values of ELR and ENLR were strongly associated with an increased risk of death and were independent indicators of poorer overall survival. Contrarily, ratios based on post-treatment blood tests had no impact on patients' prognosis.

Similarly, pre-treatment ELR and ENLR showed an impact on OS and PFS in the high-risk group, but not in the low-risk group ( $p=0.21$ and $p=0.18$, respectively), in which a limited number of events was observed.

On univariate analysis of the entire cohort, the variable age $\geq 65 y$ only trended toward significance $(p=0.055)$ but was maintained in multivariate analysis as a clinically important factor, and was significantly associated with worse OS in ENLR Cox model. In the high-risk patients (groups 4-6), age $\geq 65 y$ was an indicator of poor survival $(p=0.014$ in univariate analysis) and was proven to be an independent prognostic factor in both Cox regression models [Table 4]. By contrast, FIGO advanced stage and endometrioid histology were not significant prognosticators in the univariate analysis of high-risk patients.

ENLR was described in order to demonstrate the importance of the relation between eosinophils and lymphocytes. Subsequently, we observed that the impact on OS was constant and not influenced by the neutrophil count. As both eosinophil-based ratios have proved to be independent prognostic factors for OS, while NLR has not, we concluded that the relation between eosinophils and lymphocytes was not

Table 4 Impact of ELR and ENLR on overall survival (OS): Kaplan-Meier survival analysis, univariate and multivariate Cox regression (models for ELR and ENLR, respectively) in high-risk patients (ESMO-ESGO-ESTRO groups 4-6, $n=91$ )

\begin{tabular}{|c|c|c|c|c|c|c|c|c|}
\hline \multirow[t]{2}{*}{ Variables } & \multicolumn{2}{|c|}{$\begin{array}{l}\text { Kaplan-Meier } \\
\text { survival analysis }\end{array}$} & \multicolumn{2}{|c|}{$\begin{array}{l}\text { UNIVARIATE Cox } \\
\text { regression }\end{array}$} & \multicolumn{2}{|c|}{$\begin{array}{l}\text { MULTIVARIATE Cox regression } \\
\text { for } E L R \geq 0.1 \text { model }\end{array}$} & \multicolumn{2}{|c|}{$\begin{array}{l}\text { MULTIVARIATE Cox regression } \\
\text { for ENLR } \geq 0.5 \text { model }\end{array}$} \\
\hline & $x 2$ & $p$-value & HR (IC 95\%) & $p$-value & HR (IC 95\%) & $p$-value & HR (IC 95\%) & $p$-value \\
\hline Age $\geq 65$ years (vs. $<65$ years) & 6.9 & 0.008 & $3.7(1.3-10.5)$ & 0.014 & $3.2(1.03-10.3)$ & 0.045 & $3.2(1.1-9.7)$ & 0.038 \\
\hline FIGO advanced stage III (vs. stage I-II) & 2.2 & 0.135 & $2.1(0.8-5.7)$ & 0.143 & $2.6(0.8-8.6)$ & 0.109 & $2.5(0.8-7.7)$ & 0.104 \\
\hline Tumour grade 3 (vs. grade 1-2) & 6.7 & 0.010 & $5.6(1.3-24.5)$ & 0.022 & $6.9(1.5-31.6)$ & 0.013 & $5.8(1.3-26.3)$ & 0.023 \\
\hline Endometroid histology (vs. other histology) & 1.7 & 0.194 & $0.5(0.2-1.4)$ & 0.202 & $0.5(0.2-1.5)$ & 0.195 & $0.5(0.2-1.6)$ & 0.257 \\
\hline$E L R \geq 0.1$ (vs. $<0.1)$ & 3.9 & 0.047 & $3.3(1.3-8.7)$ & 0.014 & $4.6(1.7-12.5)$ & 0.002 & - & - \\
\hline ENLR $\geq 0.5$ (vs. $<0.5$ ) & 5.4 & 0.020 & $3.0(1.1-7.7)$ & 0.026 & - & - & $3.9(1.6-9.8)$ & 0.011 \\
\hline
\end{tabular}

All entries in boldface reflect $p$-values $<0.05$ 
affected by the presence of neutrophils, which may be interpreted as a superiority of eosinophil-based ratios over NLR and Platelet-to-Lymphocytes Ratio (PLR) (Additional file 8: Figure S8).

Our study presents some limitations, being a retrospective single institution cohort with a relatively small number of patients, which may produce potential confounding biases. However, almost all studies that deal with systemic inflammation biomarkers are of retrospective nature [7-9, 29, 30]. Confirming the cut-off points for ELR and ENLR in a larger cohort, preferably in a multicentre study, would be important for any future investigation.

In our opinion, the most important potential bias in the application of the biomarkers of systemic inflammation in clinical practice is the short life span of the WBC in systemic circulation. Consequently, it is difficult to completely rule out a potential influence of some temporary acute immunological changes, such as asymptomatic infections, on the systemic inflammatory response.

We are convinced that our investigation may contribute to a new stratification of EC and to further immunotherapy research that aim at the eosinophilic-mediate anti-tumour response.

\section{Conclusions}

Our study presents a new concept of the role of eosinophils in cancer progression that may be used as a novel prognostic tool for EC stratification. Increased values of eosinophil-related ratios based on pre-treatment blood tests are associated with worse OS in all EC patients and in high-risk patients of the ESMO-ESGO-ESTRO modified risk assessment. Impact of ELR and ENLR on PFS did not achieve statistical significance.

According to these results, the described ratios are of interest for EC prognosis and should be considered in the pre-treatment analysis. To our best knowledge, this is the first report that describes and analyses eosinophil-related ratios as prognostic indicators in cancer patients.

\section{Additional files}

Additional file 1: Figure S1. Overall survival according to FIGO stage ( $n$ $=163$ ). Kaplan-Meier survival analysis $(p=0.004$ Log Rank, $p=0.013$ Breslow test). (DOCX $64 \mathrm{~kb}$ )

Additional file 2: Figure S2. Overall survival according to tumour grade $(n=163)$. Kaplan-Meier survival analysis $(p=0.001$ Log Rank, $p=0.023$ Breslow test). (DOCX $70 \mathrm{~kb}$ )

Additional file 3: Figure S3. Overall survival according to ESMO-ESGOESTRO risk assessment ( $n=163$ ): high-risk (groups $1-3$ ) vs. low-risk (groups 4-6). Kaplan-Meier survival analysis ( $p=0.007$ Log Rank, $p=0.005$ Breslow test). (DOCX $77 \mathrm{~kb}$ )

Additional file 4: Figure S4. Overall survival according to tumour histology $(n=163)$ : endometrioid vs. non endometrioid ( $p=0.001$ Log Rank, $p=0.004$ Breslow test). (DOCX $66 \mathrm{~kb}$ )
Additional file 5: Figure S5. Overall survival according to patients' age at diagnosis $(n=163)$. Kaplan-Meier survival analysis ( $p=0.047$ Log Rank, $p=0.036$ Breslow test). (DOCX $70 \mathrm{~kb}$ )

Additional file 6: Figure S6. Overall survival of patients in High Risk (risk groups 4-6 of ESMO 2015 classification) stratified by Eosinophil-toLymphocytes Ratio (ELR) according to cut-off 0.1. (DOCX $65 \mathrm{~kb}$ )

Additional file 7: Figure S7. Overall survival of patients in High Risk (Risk groups 4-6 of ESMO 2015 classification) stratified by Eosinophil*Neutrophil-to-Lymphocytes Ratio (ENLR) according to cut-off 0.5. (DOCX $65 \mathrm{~kb})$

Additional file 8: Figure S8. ROC curves for ELR, ENLR, NLR and Platelet-to-Lymphocytes Ratio (PLR). (DOCX 81 kb)

\section{Abbreviations}

AUC: Area Under Curve; BR: Breslow test; DAMPs: Damage-associated molecular patterns; EBRT: External Beam Radiotherapy; EC: Endometrial Cancer; ELR: Eosinophil-to-Lymphocytes Ratio; ENLR: Eosinophil*Neutrophilto-Lymphocytes Ratio; ESMO-ESGO-ESTRO: European Society for Medical Oncology, European Society for Radiotherapy \& Oncology, European Society of Gynaecological Oncology; FIGO: International Federation of Gynaecology and Obstetrics; Gy: Gray; HDR-BT: High Dose Rate Brachytherapy; HIV: Human Immunodeficiency Virus; HR: Hazard Ratio; LR: Log rank test; NLR: Neutrophilto-Lymphocytes ratio; OS: Overall Survival; PFS: Progression Free Survival;

TABE: Tumour-associated blood eosinophilia; TATE: Tumour-associated tissue eosinophilia; X2: Chi-square test; $y$ : Years

\section{Acknowledgements}

This work was supported by a grant from the University of Barcelona.

Funding

There was no specific funding for this study.

Availability of data and materials

The datasets used and/or analysed during the current study are available as supplementary material.

\section{Authors' contributions}

This article was principally written by $\mathrm{KH}$, with review contributions from $A B$. Both authors have read and approved the final version of the manuscript. Some preliminary results of this study were presented last year at the 36th ESTRO Annual Meeting held in Vienna and at the 55th Annual Meeting of the Japanese Society of Clinical Oncology in Yokohama, Japan.

\section{Ethics approval and consent to participate}

Our study was approved by the Ethical Committee of Hospital Clinic de Barcelona. All patients included in the study signed the informed consent for treatment, data processing and publication.

\section{Competing interest}

The authors declare no conflict of interest.

\section{Publisher's Note}

Springer Nature remains neutral with regard to jurisdictional claims in published maps and institutional affiliations.

Received: 10 July 2018 Accepted: 26 November 2018

Published online: 22 December 2018

References

1. Siegel RL, Miller KD, Jemal A. Cancer. Statistics, 2013. CA Cancer J Clin. 2017; 67:7-30.

2. Pecorelli S. Revised FIGO staging for carcinoma of vulva, cervix and endometrium. Int J Gynaecol Obstet. 2009;105:103-4.

3. De Boer SM, Powell ME, Mileshkin L, Katsaros D, Bessette P, Haie-Meder C, et al. Toxicity and quality of life after adjuvant chemoradiotherapy versus radiotherapy alone for women with high-risk endometrial cancer (PORTEC3): an open-label, multicentre, randomised, phase 3 trial. Lancet Oncol. 2016; 17:1114-26. 
4. Colombo N, Creutzberg C, Amant F, Bosse T, González-Martín A, Ledermann J, Marth C, Nout R, Querleu D, Mirza MR, Sessa C. ESMO-ESGO-ESTRO endometrial consensus conference working group. ESMO-ESGO-ESTRO consensus conference on endometrial cancer: diagnosis, treatment and follow-up. Radiother Oncol. 2015;117:559-81.

5. Ballester M, Bendifallah S, Darai E. European guidelines (ESMO-ESGP-ESTRO consensus conference) for the management of endometrial cancer. Bull Cancer. 2017;104:1032-8.

6. Guthrie GJ, Charles KA, Roxburgh CS, Horgan PG, McMillan DC, Clarke SJ. The systemic inflammation-based neutrophil-lymphocyte ratio: experience in patients with cancer. Crit Rev Oncol Hematol. 2013;88:218-30.

7. Ethier JL, Desautels DN, Templeton AJ, Oza A, Amir E, Lheureux S. Is the neutrophil-to-lymphocyte ratio prognostic of survival outcomes in gynaecologic cancers? A systematic review and meta-analysis. Gynecol Oncol. 2017:145:584-94.

8. Cummings M, Merone L, Keeble C, Burland L, Grzelinski M, Sutton K, Begum N, Thacoor A, Green B, Saveswaran J, Huston R, Orsi NM. Preoperative neutrophil:lymphocyte and platelet:lymphocyte ratios predict endometrial cancer survival. Br J Cancer. 2015:113:311-20.

9. Hannuma T, Nakamura K, Nichida T, Ogawa C, Kusumoto T, Seki N. Pretreatment neutrophil to lymphocyte ratio is a predictor of prognosis in endometrial cancer. Anticancer Res. 2015;35:337-43.

10. Reichman H, Karo-Atar D, Munitz A. Emerging roles for eosinophils in the tumour microenvironment. Trends Cancer. 2016;2:664-75.

11. Divack DM, Janovski NA. Eosinophilia encountered in female genital organs. Am J Obstet Gynecol. 1962;84:761-3.

12. Dellon AL, Hume RB, Chretien PB. Eosinophilia in bronchogenic carcinoma. N EnglJ Med. 1974;291:207-8.

13. Mingomataj MC. Eosinophil-induced prognosis improvement of solid tumors could be enabled by their vesicle-mediated barrier permeability induction. Med Hypotheses. 2008;70:582-4.

14. Long H, Lio W, Wang L, Lu Q. A player and coordinator: the versatile roles of eosinophils in the immune system. Transfus Med Hemother. 2016;43:96-108.

15. Gatault S, Legrand F, Delbeke M, Loiseau S, Capron M. Involvement of eosinophils in the anti-tumor response. Cancer Immunol Immunother. 2012; 61:1527-34.

16. Isaacson $\mathrm{NH}$, Rapoport P. Eosinophilia in malignant tumours: its significance. Ann Intern Med. 1946;25:893-902.

17. Legrand F, Woerly G, Driss V, Capron M. Innate immune function of eosinophils: from antiparasite to antitumor cells. Methods Mol Biol. 2008; 415:215-40.

18. Hogan SP, Rosenberg HF, Mogbel R, Phipps S, Foster PS, Lacy P, Kay AB, Rothenberg ME. Eosinophils: biological properties and role in health and disease. Clin Exp Allergy. 2008;38:709-50.

19. Carretero R, Sektioglu IM, Garbi N, Salgado OC, Beckhove P, Hammerling GJ. Eosinophils orchestrate cancer rejection by normalizing tumour vessels and enhancing infiltration of CD8 (+) T cells. Nat Immunol. 2015;16:609-17.

20. Moreira A, Leisgang W, Schuler G, Heinzerling L. Eosinophilic count as a biomarker for prognosis of melanoma patients and its importance in the response to immunotherapy. Immunotherapy. 2017;9:115-21.

21. Costello R, O'Callaghan T, Sébahoum G. Eosinophils and antitumour response. Rev Med Interne. 2005;26:479-84.

22. Sakkal S, Miller S, Apostolopoulos V, Nurgali K. Eosinophils in Cancer: Favourable or unfavorable? Curr Med Chem. 2016;23:650-66.

23. Murray RC. The use of the absolute eosinophil count in the diagnosis of neoplasms - preliminary report. N Engl J Med. 1953;248:848-50.

24. Lowe D, Jorizzo J, Hutt MS. Tumour-associated eosinophilia: a review. J Clin Pathol. 1981:34:1343-8.

25. Lofti K, Kaltenmeier C, Lotze MT, Bergman C. Until death do us part: necrosis and oxidation promote the tumor microenvironment. Transfus Med Hemother. 2016;43:120-32.

26. Davis BP, Rothenberg ME. Eosinophils and cancer. Cancer Immunol Res, 2014;2:1-8.

27. Granulocytes MK. Eosinophils enable the antitumor T cell response. Nat Rev Immunol. 2015;15:333.

28. Curran CS, Bertics PJ. Eosinophils in glioblastoma biology. J Neuroinflammation. 2012;9:11.

29. Samoszuk M. Eosinophils and human cancer. Histol Histopathol. 1997:12:807-12

30. Bendifallah $\mathrm{S}$, Canlorbe $\mathrm{G}$, Collinet $\mathrm{P}$, et al. Just how accurate are the major risk stratification system for early-stage endometrial cancer? Br J Cancer. 2015;112:793-801.

\section{Ready to submit your research? Choose BMC and benefit from:}

- fast, convenient online submission

- thorough peer review by experienced researchers in your field

- rapid publication on acceptance

- support for research data, including large and complex data types

- gold Open Access which fosters wider collaboration and increased citations

- maximum visibility for your research: over $100 \mathrm{M}$ website views per year

At $\mathrm{BMC}$, research is always in progress.

Learn more biomedcentral.com/submissions 